\section{Chronic campylobacter colitis and uveitis in patient with hypogammaglobulinaemia}

Campylobacter jejuni and coli are recognised causes of enteritis, and self limiting diarrhoea is a common symptom. ${ }^{1}$ Occasionally the disease resembles Crohn's disease and ulcerative colitis. Chronic infection occurs rarely but has been reported in children and patients with immunodeficiency. ${ }^{2}$ We report on a patient with immunodeficiency with chronic diarrhoea in whom $C j e j u n i$ was repeatedly isolated and acute anterior uveitis occurred.

\section{Case report}

The patient, a woman, had undergone splenectomy for thrombocytopenia at age 34. In 1974 hypogammaglobulinaemia was diagnosed and treated by gammaglobulin replacement. In 1976 she developed haemolytic anaemia, which was controlled with steroids and two short courses of vinca alkaloids. At that time she started complaining of watery diarrhoea four to six times a day, for which no microbiological cause was found but which improved whenever her steroid dose was increased to control the anaemia. By 1978 she was passing up to 15 watery motions a day, and stool cultures showed $C$ jejuni sensitive to erythromycin and tetracycline. She was given erythromycin $500 \mathrm{mg}$ four times a day for three weeks, with no effect on her symptoms or the stool cultures. Her haemolytic anaemia remitted in 1979 , and the steroids were gradually withdrawn; her diarrhoea worsened simultaneously. In 1981 she had an episode of acute unilateral uveitis, which was treated with oral steroids, and again her diarrhoea improved.

She was later investigated in hospital several times. $C$ jejuni was isolated from her stool on five occasions; two isolates were serotyped and shown to be identical. No giardia, cryptosporidia, or other pathogens were found, and electron microscopy of the stool showed no virus particles. A smallbowel enema was normal apart from the appearance of backwash ileitis. Colonoscopy showed diffuse colitis with multiple small ulcers. Histological examination of the mucosa showed mild inflammation with aphthoid ulceration, neutrophils, no plasma cells, and incipient crypt abscesses, which suggested an infectious cause. Total white cell count was $1660 \times 10^{9} / 1$ (lymphocytes $700 \times 10^{9} / 1$, eosinophils $200 \times 10^{9} / 1$ ). The urinary concentration of indicans and faecal fat excretion were normal. A Schilling test showed abnormally low vitamin $B_{12}$ uptake, which was not altered by intrinsic factor. Culture of jejunal biopsy tissue showed moderate growth of commensal bacteria ( $10^{5}$ organisms $/ g$ tissue), as is commonly found in patients with hypogammaglobulinaemia, ${ }^{3}$ and $C$ jejuni $\left(5 \times 10^{4}\right.$ organisms/g tissue) Immunofluorescence techniques using rabbit antibody to $C$ jejuni showed organisms on the surface of the colonic mucosa but no submucosal penetration

She was treated with one 15 day course of tetracycline $500 \mathrm{mg}$ four times daily, five courses of oral erythromycin with doses up to $500 \mathrm{mg}$ four times daily for four weeks, and intravenous gammaglobulin (Sandoglobulin, Sandoz) $9.3 \mathrm{~g}$ fortnightly for two months, which did not clear the organism from her stool. On her last admission to hospital in 1982 her diarrhoea was worse and she had lost weight. She was given intravenous erythromycin $600 \mathrm{mg}$ thrice daily for two weeks followed by $500 \mathrm{mg}$ four times daily by mouth for two weeks. Within two days of the start of treatment her bowel frequency had fallen from six to two motions a day. Stool cultures were negative for $C j e j u n i$ and she had no diarrhoea over nine months follow up.

\section{Comment}

This case is of interest because uveitis has not been reported in association with $C$ jejuni colitis and is not a recognised complication of hypogammaglobulinaemia. Some clinical and radiological features in our patient such as her symptomatic response to steroids were consistent with Crohn's colitis, but the histological findings indicated an infectious cause. ${ }^{4}$ Despite her immunodeficiency and steroid treatment our patient had apparently harboured $C$ jejuni infection for about six years without evidence of systemic spread, which confirms that the organism's pathogenicity is mediated by production of enterotoxin. ${ }^{5}$ We suggest that high dose intravenous erythromycin may be effective treatment for chronic watery diarrhoea in patients with hypogammaglobulinaemia.

We thank Dr J L Penner, department of medical microbiology, University of Toronto, for carrying out the serotyping.

' Butzler JP, Skirrow MB. Campylobacter enteritis. Clin Gastroenterol $1979 ; 8: 737-65$

2 Ponka A, Tilvis R, Kosunen TU. Prolonged campylobacter gastroenteritis in a patient with hypogammaglobulinaemia. Acta Med Scand $1983 ; 213: 159-60$

3 Webster ADB. The gut and immunodeficiency disorders. Clin Gastroenterol $1976 ; 5: 323-40$.
4 Price AB, Day DW. Pseudomembranous and infectious colitis. In: Anthony PP, MacSween RNM, eds. Recent advances in histopathology. Edinburgh: Churchill Livingstone, 1981;11:99-117.

${ }^{5}$ Ruiz-Palacios GM, Torres J, Torres NI, Escammila E, Ruiz-Palacios BR, Tamayo T. Cholera-like enterotoxin produced by Campylobacter jejuni. Lancet 1983 ;ii :250-3.

(Accepted 2 November 1983)

Clinical Research Centre, Harrow, Middlesex

A M L LEVER, BSC, MRCP, research registrar

J M DOLBY, PHD, senior scientist (microbiology)

A D B WEBSTER, FRCP, senior scientist and consultant physician

Northwick Park Hospital, Harrow, Middlesex

A B PRICE, FRCPATH, consultant histopathologist

Correspondence to: Dr A M L Lever, Division of Immunological Medicine, Clinical Research Centre, Watford Road, Harrow, Middlesex HA1 3UJ.

\section{Oral acyclovir in eczema herpeticum}

Eczema herpeticum is one type of Kaposi's varicelliform eruption. It usually affects patients with atopy who suffer from active eczema, but those whose eczema is in remission may also contract it. People with rare disorders such as pemphigus foliaceus or Darier's disease (keratosis follicularis) are also susceptible. The severity of the infection ranges from localised and mild to widespread and fatal. Patients may die of viraemia, organic complications, or massive secondary bacterial infection, although most recover.

The growth in public awareness of infection with Herpesvirus hominis and the increasing incidence of certain varieties of the infection $^{1}$ will lead to widened use of the antiherpetic drug acyclovir. I report on two children with eczema herpeticum who were treated with oral acyclovir.

\section{Case reports}

Case 1-An 11 year old Sikh boy with lifelong, severe atopic eczema and asthma was admitted to hospital acutely ill with fever, enlarged glands, and widespread impetiginised fissured plaques of eczema, which were most pronounced on his face, neck, and upper trunk. Blood cultures showed contamination with Staphylococcus epidermidis, and multiple skin swabs showed heavy growth of $S$ aureus and $\beta$ haemolytic streptococcus group $G$. He was treated with intramuscular erythromycin, potassium permanganate soaks, and sodium fusidate ointment. With this treatment the crusting slowly cleared and underlying groups of herpetiform vesicles could be detected. Because of the degree of sepsis only a scanty quantity of vesicular fluid was obtained for viral culture, but this confirmed a diagnosis of herpes simplex infection. After 48 hours' observation the groups of vesicles seemed to be spreading and he was given oral acyclovir $100 \mathrm{mg}$ every four hours five times daily for five days. This dose was equivalent to $25 \mathrm{mg} / \mathrm{kg}$ body weight/day. No

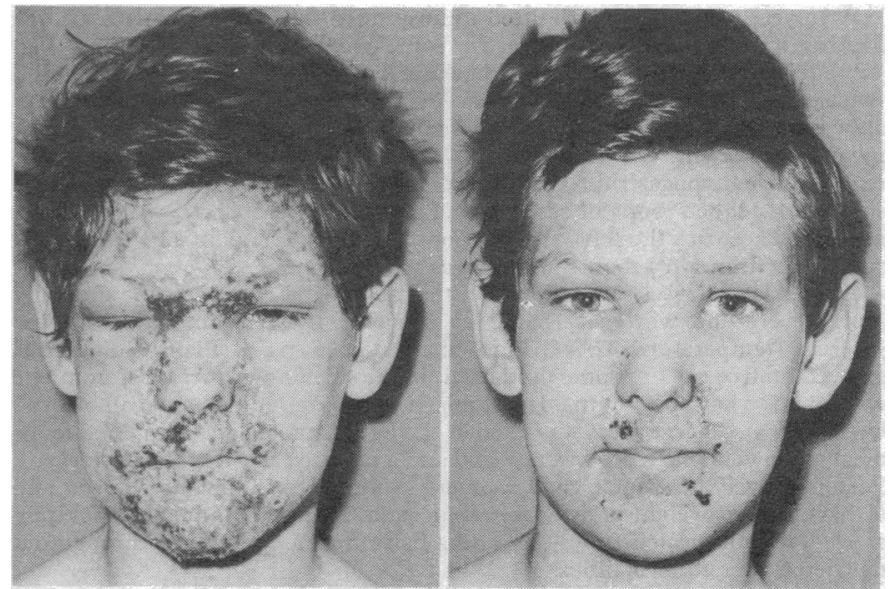

Case 2. Herpetiform eruption before (left) and after (right) treatment with acyclovir. 
fresh lesions were seen, and his general condition and the lesions improved rapidly.

Case 2-A 12 year old European boy was admitted with fever, considerable herpetiform eruption on his face and neck, and severe angio-oedema of periorbital tissues (figure). The eruption had begun four to five days previously and had spread explosively. He had a history of atopic eczema from infancy, but there had been good spontaneous improvement over the past year or two. No pyogenic organisms were isolated from repeated blood cultures and multiple skin swabs. Virus culture confirmed a diagnosis of herpes simplex infection. The vesicles continued to spread and disseminate, and he was given oral acyclovir $200 \mathrm{mg}$ every four hours five times daily for five days. This dosage was equivalent to $25 \mathrm{mg} / \mathrm{kg}$ body weight/day. No further eruption of herpetic lesions occurred (figure), and no evidence of herpetic infection was detected in his eyes. He was also treated with flucloxacillin and sodium fusidate ointment to prevent secondary bacterial infection.

\section{Comment}

Both these patients showed a good clinical response to oral treatment with acyclovir, and the infection did not recur during three months of follow up. This treatment caused no discomfort to the patients and had no apparent side effects. ${ }^{2}$ There is not yet an established dosage for children, ${ }^{3}$ and possibly a higher dosage than was used in these children might have been more beneficial as their renal function was normal and only $20 \%$ of acyclovir is absorbed from the gut. ${ }^{4}$

${ }^{1}$ Fawcett HA, Wansbrough-Jones MH, Clark AE, Leigh IM. Prophylactic topical acyclovir for frequent recurrent herpes simplex infection with and without erythema multiforme. Br Med F 1983;287:798-9.

2 Swart RNJ, Vermeer BJ, Der Meer JWM, Enschede FAJ, Versteeg J. Treatment of eczema herpeticum with acyclovir. Arch Dermatol 1983; 119:13-6.

${ }^{3}$ Gould JM, Chessells JM, Marshall WC, McKendrick GDW. Acyclovir in herpesvirus infections in children. Fournal of Infection 1982;5:283-9.

4 Wellcome Medical Division. Zovirax. Beckenham, Kent: Burroughs Wellcome, 1983. (Data sheet.)

\section{Cuboidal calcium enterolith causing obstruction and perforation of small intestine}

Intestinal strictures are a rare cause of calcium enteroliths, and perforation as a complication has only once been reported. ${ }^{1}$ We report on a patient with a cuboidal enterolith; this has never previously been described.

\section{Case report}

A 56 year old man was admitted to hospital as an emergency with a three day history of intermittent epigastric pain, which had been severe but had subsequently eased off. He reported having had similar episodes of pain about twice a year for the past few years. His only medical history was of an appendicectomy when he was 11 years old. He had not received any recent medical treatment. On admission his abdomen was slightly distended and tender in the hypogastrium, with increased bowel sounds. Plain radiographs showed distended loops of small bowel and a square opacity, with a lucent centre, adjacent to the left sacroiliac joint (figure). The pain and tenderness resolved within a few hours and he was allowed home.

A week later he was readmitted. On that day the pain had become suddenly more severe and was exacerbated by movement. On examination he was feverish (temperature $37.7^{\circ} \mathrm{C}$ ) and his abdomen rigid. Plain radiographs showed no free gas but some fluid levels in the small bowel. At laparotomy he was found to have peritonitis. His stomach, duodenum, liver, and gall bladder were normal. A large mass was fixed in the left iliac fossa and contained loops of small bowel. The mass was resected and a primary anastomosis performed. Postoperatively he made a good recovery. Subsequent follow up showed him to have gained weight and to be free of pain. Plain abdominal radiography showed no other calcified lesions, and a barium meal and follow through did not detect any abnormalities.

In the resected ileum a $2 \mathrm{~cm}$ perforation was found $2.5 \mathrm{~cm}$ proximal to an impacted cuboidal hard stone $1.7 \times 1.5 \times 1.2 \mathrm{~cm}$. Immediately distal to the stone was a fibrous stenosis of the bowel wall. The proximal segment showed muscular hypertrophy and two ulcerated areas, one of which had perforated There were no specific features present and in particular no evidence of Crohn's disease, tuberculosis or an ischaemic aetiology.

The stone had hard outer walls composed almost entirely of calcium oxalate. The soft brown core contained some histologically identifiable plan material. Electron probe analysis of the wall confirmed the high calcium content. The patient could not recall having ingested any cuboidal vegetable or fruit.

\section{Comment}

Calcium enteroliths are rare and usually develop in the distal small bowel. They are associated with stasis, often related to an intestinal stricture caused by tuberculosis or Crohn's disease. ${ }^{2}$ The more common type of enterolith has a high content of choleic acid and develops in acquired or congenital diverticulums."

Many enteroliths are thought to form around a nucleus, which is usually of plant material, especially fruit skins and stones. Experimental studies have shown that ingested material that swells may cause an obstruction and that oblong objects are slower in their progress through the bowel than round objects. ${ }^{4}$ Fruit pith and skins may produce an ileus at a site of slight stenosis. ${ }^{5}$

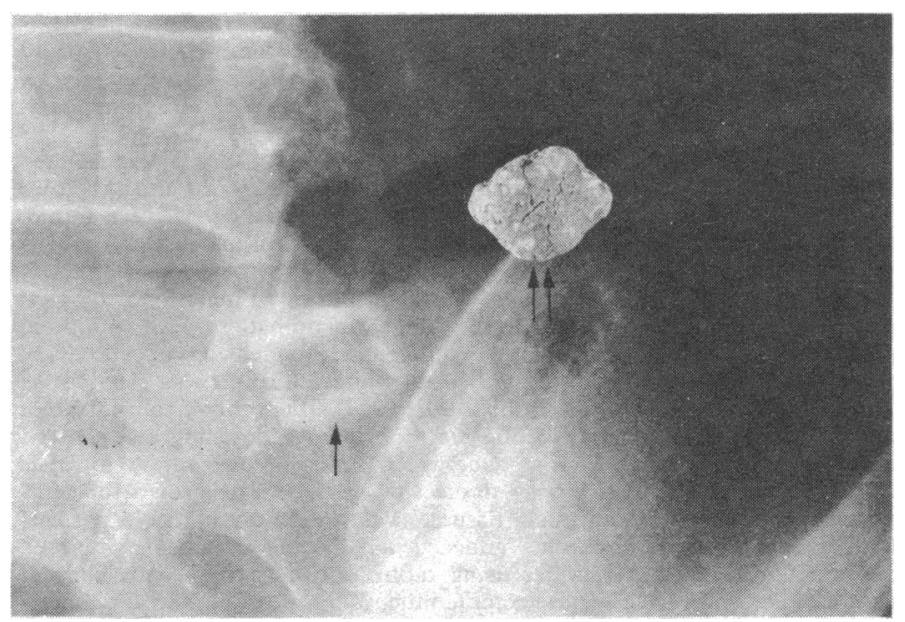

Close up of plain abdominal radiograph recorded on admission showing square opacity with lucent centre $(\uparrow)$. Enterolith after removal is superimposed $(\uparrow \uparrow)$.

Our patient's long history of intermittent colic suggests that the enterolith had been present at that site for some time and a source of mucosal irritation with subsequent fibrosis. We believe that the most likely course of events was impaction of ingested plant material at a slight ileal stricture without obstruction; formation of a crust of calcium oxalate around this nucleus; excitation of chronic inflammation and fibrosis leading to further narrowing of the segment of the bowel; and finally complete obstruction and perforation. The curious, precise cuboidal shape of the enterolith remains unexplained.

We thank Mr J B Bourke for allowing us to report on his patient and for his help.

1 Zeit RM. Enterolithiasis associated with ileal perforation in Crohn's disease. Am $\mathcal{F}$ Gastroenterol 1979;72:662-4.

2 Atwell JD, Pollock AV. Intestinal calculi. Br f Surg 1960;47:367-74.

${ }^{3}$ Shockett E, Simon SA. Small bowel obstruction due to an enterolith formed in a duodenal diverticulum. A case report and review of the literature. Am $\mathcal{F}$ Gastroenterol 1982;77:621-4.

4 Harjola PT, Scheinin TM. Experimental observations on intestinal obstruction due to foreign bodies. Acta Chir Scand 1963;126:144-7.

5 Ward-McQuaid N. Intestinal obstruction due to food. $B r \operatorname{Med} \mathcal{F} 1950$; : 1106-9.

(Accepted 2 November 1983)

University Hospital, Nottingham NG7 2UH

JENNY WALKER, FRCSE, registrar in surgery

IAN O ELLIS, BM, BS, lecturer in histopathology

Correspondence to: Miss Jenny Walker. 